\title{
Syndrome of Congenital Insulin Resistance Caused by a Novel INSR Gene Mutation
}

\section{Rojek A et al. Syndrome of Congenital Insulin Resistance}

\author{
Aleksandra Rojek ${ }^{1}$, Beata Wikiera ${ }^{2}$, Anna Noczynska ${ }^{2}$, Marek Niedziela ${ }^{3}$ \\ ${ }^{1}$ Poznan University of Medical Sciences, Institute of Pediatrics, Department of Pediatric Endocrinology and Rheumatology, \\ 27/33 Szpitalna Street, 60-572 Poznan, Poland \\ ${ }^{2}$ Wroclaw Medical University, Department of Endocrinology and Diabetology for Children and Adolescents, $13 \mathrm{c}$ Josef \\ Hoene-Wronski Street, 50-376 Wroclaw, Poland \\ ${ }^{3}$ Poznan University of Medical Sciences, Institute of Pediatrics, Department of Pediatric Endocrinology and Rheumatology, \\ Karol Jonscher's Clinical Hospital 27/33 Szpitalna Street, 60-572 Poznan, Poland
}

\begin{abstract}
What is already known about this topic?
- $\quad$ Leprechaunism (Donohue syndrome) is the most severe form of insulin resistance caused by autosomal recessive mutations in the insulin receptor gene and is characterized by extreme insulin resistance leading to hyperinsulinemia, impaired glucose homeostasis and prenatal and postnatal growth retardation.

- Moreover, dysmorphic features, hypertrichosis, acanthosis nigricans, macrogenitosonia, and polycystic ovaries and breast enlargement in females are also present, and common complications include hypertrophy of internal organs. Patients with leprechaunism usually die in the first year of life.

\section{What does this study add?}

- The study describes a novel mutation in the INSR gene in the patient with Donohue Syndrome

- This case highlights the importance of genetic testing of the INSR gene, which is crucial for genetic counseling as well as for improving the prognosis of patients with severe insulin resistance syndromes; the prognosis may strongly depend on the type and location of the INSR gene mutation.

- $\quad$ Moreover, until now, there have been no reports of fatty liver disease in patients with proven loss of function of the insulin receptor, which raises the question of whether it plays a role in prognosis.

- The study also highlights the challenges faced by clinicians in the management of this complex, rare condition.
\end{abstract}

\begin{abstract}
Mutations in the insulin receptor gene result in rare inherited syndromes causing insulin resistance, such as leprechaunism (Donohue syndrome), Rabson-Mendenhall syndrome and insulin resistance type A. Leprechaunism is an autosomal recessive disorder associated with extreme insulin resistance that leads to hyperinsulinemia, impaired glucose homeostasis, fasting hypoglycemia and postprandial hyperglycemia inpaired insulin action causes prenatal and postnatal growth retardation. Lipoatrophy, dysmorphic facies, hypertrichosis, macrogenitosomia and hypertrophy of internal organs are also present. A male infant with congenital insulin resistance was born at term after a normal pregnancy with a weight of $1905 \mathrm{~g}(<3 \mathrm{c})$, a length of $48 \mathrm{~cm}(<3 \mathrm{c})$, and an Apgar score of 10. Intrauterine growth retardation, transient hypoglycemia, pneumonia, urinary tract infection and heart defects (PFO - patent foramen ovale; PDA - patent ductus arteriosus) were diagnosed after birth. At 5 weeks of age, he was admitted to the egional hospital with severe fever, diarrhea and dehydration. Hyperglycemia was observed $(672 \mathrm{mg} / \mathrm{dl})$, and insulin was administered. He was referred to a hospital at 7 weeks of age for suspected neonatal diabetes and hypertrophic cardiomyopathy. The physical examination revealed a loud systolic heart murmur, tachycardia, tachypnea, dysmorphic facies, hypertrichosis, acanthosis nigricans, hypotonia, swollen nipples and enlarged testicles. Glycemic fluctuations $(50-250 \mathrm{mg} / \mathrm{dl})$ were observed. The serum insulin concentration was high (maximum $1200 \mathrm{IU} / \mathrm{ml})$ at normoglycemia. Ultrasound of the heart confirmed progressive hypertrophic cardiomyopathy. Leprechaunism was confirmed by genetic analysis of the insulin receptor (INSR) gene, in which a novel c.320C $>\mathrm{G}$; p. Thr107Arg homozygous missense mutation in exon 2 was found.
\end{abstract}

Keywords: Insulin receptor, insulin resistance, leprechaunism

Prof. Marek Niedziela, MD, PhD, Poznan University of Medical Sciences, Institute of Pediatrics, Department of Pediatric Endocrinology and Rheumatology, Karol Jonscher's Clinical Hospital, 27/33 Szpitalna Street, 60-572 Poznan, Poland $+48618491481$ marek.niedziela@ump.edu.pl 0000-0001-8862-6937

31.07.2021

22.11.2021

Published: 30.12 .2021

\section{Introduction}

Insulin participates in a variety of biochemical processes, such as the metabolism of carbohydrates, lipids and proteins. It also influences cell proliferation, differentiation and apoptosis. It fulfills the role of a growth factor and a regulator of gene expression and contributes to protein biosynthesis (1). 
Insulin acts through a specific insulin receptor (INSR), which is encoded by a gene (Gene ID: 3643, OMIM: *147670) located on the short arm of chromosome 19 (19p13.3) composed of 22 exons (2). The mature insulin receptor functions as a heterotetramer consisting of two dimers of two subunits ( $\alpha$ and $\beta$, respectively). The $\alpha$ subunit is an extracellular ligand binding domain, whereas the intracellular $\beta$ subunit functions as the catalytic domain of the receptor $(\mathbf{3 , 4 , 5 , 6 )}$. Mutations in the INSR gene result in rare inherited syndromes of insulin resistance, such as leprechaunism (Donohue syndrome; OMIM: \#246200), Rabson-Mendenhall syndrome (RMS; OMIM \# 262190), insulin resistance type A (OMIM ID: 610549) and lipoatrophic diabetes mellitus $\mathbf{( 7 , 8 , 9 , 1 0 , 1 1 )}$.

Donohue syndrome is the most severe form of insulin resistance. It is a rare autosomal recessive disorder associated with extreme insulin resistance leading to hyperinsulinemia, impaired glucose homeostasis, fasting hypoglycemia and postprandial hyperglycemia. Impaired insulin action causes prenatal and postnatal growth retardation.

Dysmorphic features, such as prominent eyes, thick lips, a flattened nasal bridge with upturned nostrils, low-set posteriorly rotated ears and thick skin with a lack of subcutaneous fat are present. Hypertrophy of internal organs, including cardiomegaly, hepatosplenomegaly, and hypertrophy of the ovaries, is also a common complication. Moreover, hypertrichosis, acanthosis nigricans, macrogenitosomia, and polycystic ovaries and breast enlargement in females are also characteristic for children with Donohue syndrome, and in some of them, mental retardation is observed. Patients with leprechaunism usually die in the first year of life $(\mathbf{1 0}, \mathbf{1 2}, \mathbf{1 3}, \mathbf{1 4}, \mathbf{1 5})$.

Patients with Rabson-Mendenhall syndrome (RMS) develop constant hyperglycemia, diabetic ketoacidosis and other complications of diabetes mellitus, which lead to death in the $1^{\text {st }}$ or $2^{\text {nd }}$ decade of life $(\mathbf{1 6 , 1 7 , 1 8 , 1 9 , 2 0 , 2 1 )}$.

\section{Case report}

A male infant, which was the child of consanguineous, young, healthy parents from the Roma population, was admitted to the Department of Pediatric Endocrinology at the age of 7 weeks with suspected neonatal diabetes and hypertrophic cardiomyopathy. He was born at term after a normal pregnancy (Apgar 10). He was small for his gestational age, with a birth weight of $1905 \mathrm{~g}$ (SDS -3,73) and length of $48 \mathrm{~cm}$ (SDS -1,2). Intrauterine growth retardation, transient hypoglycemia, neonatal pneumonia, urinary tract infection and heart defects ( $\mathrm{PFO}$ - patent foramen ovale; PDA - patent ductus arteriosus) were diagnosed just after birth. He was released from the neonatology unit twelve days after birth. At the age of 5 weeks, he was admitted to the regional hospital in a severe state with fever, diarrhea and dehydiation. Hyperglycemia (672 mg/dl) was observed; therefore, insulin (i.v.) was administered for several days. Fluctuations in the blood glucose levels were observed afterwards $(40-410 \mathrm{mg} / \mathrm{dl})$ but unexpectedly normalized spontaneously thereafter. The child was referred to the Department of Pediatric Endocrinology at the age of 7 weeks with suspected neonatal diabetes. His body weight was $3000 \mathrm{~g}$ (SDS -2,5), and physical examination revealed a loud systolic heart murmur, tachyeardia, tachypnea, and inspiratory-expiratory dyspnea. He had multiple phenotypic anomalies, including low-set large ears, coarse facial features, a flattened nasal bridge, thickened lips, generalized hypertrichosis, acanthosis nigricans in the skin folds and over the knees, decreased subcutaneous fat, hypotonia, prominent nipples and enlarged testicles $(4 \mathrm{ml})$. Glycemic fluctuations $(50-250 \mathrm{mg} / \mathrm{dl})$ were initially observed. Postprandial hyperglycemia normalized spontaneously. Subsequently, at the age of 8 weeks, recurrent episodes of hypoglycemia occurred, and the patient required intravenous infusions of $10 \%$ glucose. The serum insulin concentration was elevated (maximum $1200 \mathrm{IU} / \mathrm{ml}$ ) at normoglycemia (Table 1). Glycated hemoglobin A1c was at the lower normal limit (4.1\%; normal 4.0-6.2\%), which demonstrates the predomination of hypoglycemic episodes over postprandial hyperglycemic episodes. Serum liver enzymes and lipids concentration fluctuated around the upper range of normal limits. Moreover, serum IGF-1 and IGFBP3 were decreased ( $<25 \mathrm{ng} / \mathrm{ml}$ (normal 55-327) and $<0,5 \mathrm{ug} / \mathrm{ml}$ (normal 0,7-3,6), respectively). Inherited metabolic disorders (amino acid and acylcarnitine profiles) were excluded based on the mass spectrometric results. Echocardiography confirmed hypertrophic cardiomyopathy with obstruction of the left ventricular outflow. A congenital heart defect (PFO) was still present and a beta-adrenoreceptor antagonist (metoprolol) was administered. Subsequent echocardiography revealed the progression of hypertrophic cardiomyopathy. A radiogram of the chest showed cardiomegaly and inflammatory changes in the lungs. Pneumonia was treated with antibiotics. The infant was stable during the subsequent four weeks following his admission to the ward. Diuretics were administered due to fluid retention. In the $5^{\text {th }}$ week of hospitalization, fever occurred, and the patient's general state deteriorated. Physical examination revealed tachycardia, a loud systolic heart murmur, intense dyspnea, whezzing, hepatomegaly and peripheral edema. Echocardiography revealed the progression of ventricular septum hypertrophy and pulmonary valve vegetation. Sepsis, endocarditis and progression of hypertrophic cardiomyopathy with severe left ventricular constriction were diagnosed. The patient was managed with antibiotic therapy and intravenous gammaglobulins after the implantation of a central venous Broviac catheter, acute postoperative respiratory failure manifested. The infant was admitted to the intensive care unit where sudden circulatory arrest occurred. Despite immediate resuscitation, the child died in the $13^{\text {th }}$ week of postnatal life. The postmortem examination demonstrated hypertrophy of both heart ventricles to a major extent, features of left and right heart insufficiency, hepatomegaly, fatty liver and digestive tract hemorrhage. The syndrome of congenital insulin resistance was diagnosed based on the clinical picture, laboratory tests and molecular analysis results.

\section{Genetic analysis of the INSR gene}

A blood sample was collected and frozen at $-20^{\circ} \mathrm{C}$ until it was analyzed. Genetic analysis of the INSR gene was performed according to all the relevant national regulations and institutional policies in accordance with the tenets of the Helsinki Declaration and was approved by the local Ethics Committee of the University (No. 146/10).

Molecular studies of the INSR gene were performed using PCR and direct sequencing. The parents of the patient were not available for genetic testing. Genomic DNA was isolated from peripheral blood leucocytes using the QIAamp ${ }^{\circledR}$ DNA Blood Mini Kit (QIAGEN). Twenty-two sets of primers were used to amplify all exons of the INSR gene. All the oligonucleotides used in this study came from IBB PAS in Poland (Institute of Biochemistry and Biophysics, Polish Academy of Science, Warsaw, Poland), and their sequences are available on request. Polymerase chain reactions (PCR) were performed in a 10$20-\mu 1$ mixture using HotStarTaq ${ }^{\circledR}$ DNA Polymerase (QIAGEN) with the following parameters: denaturation at $95^{\circ} \mathrm{C}$ for 15 min, followed by 40 cycles of $95^{\circ} \mathrm{C}$ for $60 \mathrm{~s}, 60^{\circ} \mathrm{C}$ or $58^{\circ} \mathrm{C}$ for $30 \mathrm{~s}$, and $72^{\circ} \mathrm{C}$ for $45-90 \mathrm{~s}$ (depending on the primer pair used). A final amplification at $72^{\circ} \mathrm{C}$ for 7 min completed the PCR program. The PCR products were separated by 
electrophoresis on a 1.2\%-1.5\% agarose gel in the presence of ethidium bromide (Merck), purified from the gel using a QIAquick ${ }^{\circledR}$ Gel Extraction Kit (QIAGEN) and directly sequenced with the same primer pair used for PCR. All sequencing reactions were performed using the BigDye Terminator v 3.1 cycle sequencing kit (Applied Biosystems) on an ABI Prism 3130XL Genetic Analyzer (Applied Biosystems). Finally, the sequences were analyzed using VectorNTI 9.0 Software (Invitrogen) with the reference sequence NC_000019.08 (accession date: 03.03.2008).

Results

The glucose and insulin values for the patient serum are presented in Table 1.

Results of the genetic analysis of the INSR gene

The sequence analysis revealed the presence of a novel homozygous missense mutation, c. $320 \mathrm{C}>\mathrm{G}$, in exon 2 that changed the polar threonine at position 107 into a basic arginine (p. Thr107Arg) (Figure 1). This variant was not found in control samples in the current version of the ESP6500 dataset deposited in the NHLBI Exome Variant Server, which comprises a set of 2203 African-American and 4300 European-American unrelated individuals with 6503 samples (13,006 chromosomes) in total (accession date: 25.01.2013), or in the ExAC and 1000G databases.

Three predictive tools were used to establish the overall effect of the $\mathrm{p}$. Thr107Arg mutation in the presented patient. Analysis using SIFT (Sorting Intolerant From Tolerant, http://sift.jcvi.org/), which predicts the possible impact of a substitution based on sequences of similar peptides, assigned a score of 0 to the $\mathrm{p}$. Thr107Arg mutation. This indicates that the mutation has a damaging effect on the INSR protein (the SIFT scale designates scores of less than 0.05 as deleterious, while scores of 0.05 or greater are predicted to be tolerated).

Furthermore, analysis using Mutation Taster (http://www.mutationtaster.org/) predicted the $\mathrm{p}$. Thr107Arg mutation to be "disease causing" (score: 1,94; probability $\mathrm{p}=0,99$ ).

Similarly, PolyPhen-2 (Polymorphism Phenotyping v2) software, which predicts the effects of a substitution based on the structure and function of a human protein using straightforward physical and comparative considerations

(http://genetics.bwh.harvard.edu/pph2/), predicted this mutation to be "probably damaging" based on scores of 1.000 (HumDiv, sensitivity: 0.00; specificity: 1.00) and 0.999 (HumVar, sensitivity: 0.09; specificity: 0.99).

\section{Discussion}

In this study, we present an infant boy with clinical features and laboratory data typical of leprechaunism whose diagnosis was confirmed by genetic analysis of the insulin receptor gene, in which a novel mutation was found.

Donohue syndrome (leprechaunism) was first identified in 1948 by W. L. Donohue (22). The incidence of leprechaunism has been estimated to be at least 1 in 4 million live births (7). The molecular background of insulin resistance in leprechaunism has been associated with recessive mutations of the INSR gene. Due to such mutations, aberrant receptors can no longer serve their function. Mutations in the INSR gene are extremely rare, which is why most cases of inherited severe insulin resistance result from consanguineous parents $(\mathbf{1 2 , 1 4 , 2 3 )}$ as was the case for the infant described here.

Molecular studies carried out for our patient led to the identification of the novel homozygous missense mutation c. C320 $>\mathrm{G}$ in exon 2 in the INSR gene. Only one single nucleotide polymorphism C/T (SNP) at position 320 in the INSR gene (rs 140762552, c.320C > T; p. Thr107Met) has been deposited in the SNP database (dbSNP, http://www.ncbi.nlm.nih.gov/snp) to date, but the variant described is of unknown significance. The impact of the mutation c.C $320>\mathrm{G}$ on receptor function is unknown; thus, the clinical diagnosis of leprechaunism was confirmed by in silico analysis. This novel mutation was predicted to disrupt a single-stranded right-handed beta-helix in the L-domain of the $\alpha$ subunit of INSR. This domain contains a cysteine-rich region composed of eight disulfide bonds. The three L-domains located in the $\alpha$ subunit of INSR surround a central space that is large enough to accommodate a hormone. Although the protein fragment comprising residues 1-462 does not bind insulin on its own this central site exhibits many of the features crucial for insulin binding and ligand specificity (24). Therefore, the p. Thr107Arg mutation may disrupt the ability of INSR to bind its ligand.

Longo et al. (23) investigated several patients with inherited insulin resistance syndromes and different survival times that ranged from a few weeks to several years. They distinguished two phenotypes in their patients, leprechaunism and RabsonMendenhall syndrome, and tried to establish the genotype-phenotype correlation. They identified new mutations in the INSR gene and analyzed the correlation between these mutations and the survival rate. Mutations that completely or markedly impaired insulin binding to the receptor resulted in the most severe phenotype with early death (leprechaunism), while mutations resulting in residual insulin-binding activity were associated with a longer lifespan (RMS).

We studied a patient with severe insulin resistance who had a phenotype consistent with the descriptions of patients with leprechaunism reported in the literature $(\mathbf{1 4 , 2 2 , 2 5})$. Our patient demonstrated all of the relevant disorders of carbohydrate metabolism: fasting hypoglycemia, postprandial hyperglycemia, hyperinsulinemia and severe insulin resistance. A combination of decreased hepatic glucose output in the fasting state and decreased hepatic glycogen synthesis during feeding due to a postreceptor defect in insulin action leads to fasting hypoglycemia and postprandial hyperglycemia (26).

Another consequence of insulin resistance is defects in fatty acid metabolism, which are responsible for the pathogenesis of fatty liver disease (26). The postmortem examination of our patient showed the presence of fatty liver. To date, there have been no reports of fatty liver disease in patients with proven loss of function of the insulin receptor. Donohue and Uchida presented various results of liver histological examinations, including the absence of abnormalities, nonspecific lesions consisting of focal degeneration or necrosis, and focal increases in glycogen and iron deposits (14).

Despite extreme insulin resistance, patients with primary defects at the level of the insulin receptor (generalized insulin resistance) did not manifest metabolic dyslipidemia. Despite higher plasma free fatty acids and glucose levels and massively increased plasma insulin levels, liver fat measurements were normal in the patients with insulin receptor mutations. Theoretically, this could be a result of either reduced hepatic lipogenesis or increased oxidation or excretion of liver triglycerides $(27,28)$. This patient could still have a rudimentary INSR activity and therefore could develop fatty liver disease.

Intrauterine growth retardation and postnatal failure to thrive are part of the clinical picture of congenital insulin resistance. Psiachou et al. (29) suggested that the primary defect in leprechaunism is in the insulin receptor gene and that a secondary defect is probably responsible for the impaired response to endogenous $\mathrm{GH}$ and growth retardation. According to Kadowaki 
et al. (30), the insulin receptor gene may regulate the function of IGF-I receptors. They suggested that the defect in the INSR gene impairs the functioning of receptors for other growth factors. Our patient had serum levels of IGF-1 and IGFBP-3 below the normal limits. IGF-1 plays an important role in prenatal and postnatal growth. Thus, both the defects in insulin action and the impaired synthesis of IGF-1 and IGFBP-3 resulted in growth retardation in this child. Nakae et al. proved that treatment with rhIGF-1 normalized glucose metabolism and was effective in preventing postnatal growth retardation in a patient with leprechaunism (31). Other authors, however, reported that administration of recombinant human growth hormone (rhGH) and human insulin-like growth factor 1 (rhIGF-1) had little or no influence on glucose homeostasis and none on growth stimulation. They hypothesized that this could be due to a postreceptor defect in IGF-1 signaling caused by the absence of insulin function (13).

There is evidence that insulin at high concentrations acts as a growth factor through IGF-I receptors. IGF-I receptors are present in the ovaries, kidneys and heart. This fact could explain the enlargement of these organs reported in patients with leprechaunism (30).

Recurrent bacterial infections presented an additional problem in our patient. Data from the literature show that infections occur with increased frequency in patients with leprechaunism. It is supposed that a congenital leptin deficiency due to defective insulin activity in the adipose tissue negatively influences T-cell function $(\mathbf{2 3 , 3 2})$.

There is no effective therapy for severe forms of inherited insulin resistance. The life expectancy of children with leprechaunism is poor, and early death is certain. Most patients die during the $1^{\text {st }}$ year of life $(\mathbf{1 4 , 2 2 , 2 5})$. Some patients with milder forms of the disease have lived longer, which may be related to partial activity of INSR (33).

\section{Conclusions}

In summary, we found a novel homozygous mutation in the INSR gene in a patient with severe clinical manifestations of insulin resistance, which confirmed the diagnosis of Donohue syndrome (leprechaunism). We also found the presence of fatty liver in the patient and so far, there have been no reports of fatty liver disease in patients with proven loss of function of the insulin receptor. The fatal outcome in this child demonstrated the high risk in subjects with the most severe form of the disease if the mutation occurs in the ligand-binding domain of the receptor. This rare disorder represents a challenge for further new clinical trials that may improve the prognosis of such patients.

Funding: This study was supported by funds from the Department of Pediatric Encocrinology and Rheumatology of Poznan University of Medical Sciences (No. 502-01-01104118-06037 to Marek Niedziela)

\section{Disclosure Statement}

The authors have nothing to disclose.

\section{Authorship Contribution:}

All the authors have read the manuscript, accept responsibility for its entire content and approve its submission. AR: study concept and design, molecular genetic studies, analysis and interpretation of molecular data, manuscript drafting BW: study concept and design, clinical evaluation of the patient, manuscript drafting

EG: clinical evaluation of the patient

AN: clinical evaluation of the patient, critical revision of the manuscript for important intellectual content

$\mathrm{MN}$ : study concept and design, critical revision of the manuscript for important intellectual content, funding procurement, study supervision

\section{References}

1. Fu Z, Gilbert ER, Liu D. Regulation of insulin synthesis and secretion and pancreatic beta-cell dysfunction in diabetes. Curr Diabetes Rev. 2013;9(1):25-53.

$2 . \quad$ Insulin receptor no. 147670: đefect in insulin receptor, with insulin resistant diabetes mellitus, acanthosis nigricans, and Type A. Online Mendelian Inheritance in Man (OMIM). Johns Hopkins University. Victor A. McKusick. 6/2/1986. http://www.ncbi.nlm.nih.gov/entrez/dispomim. cgi?id=147670.

3. Ullrich A, Bell JR, Chen EY et al. Human insulin receptor and its relationship to the tyrosine kinase family of oncogenes. Nature 1985;313:756-761.

4. De Meyts P, Whittaker J. Structural biology of insulin and IGF1 receptors: implications for drug design. Nat Rev Drug Discov 2002;1:769-783.

5. Sesti G, Federici M, Lauro D, Sbraccia P, Lauro R. Molecular mechanism of insulin resistance in type 2 diabetes mellitus: role of the insulin receptor variant forms. Diabetes Metab Res Rev 2001;17:363-373.

6. Kristensen C, Wiberg FC, Schaffer L, Andersen AS. Expression and characterization of a 70-kDa fragment of the insulin receptor that binds insulin. J Biol Chem 1998;273:17780-17786.

7. Taylor SI, Kadowaki T, Kadowaki H, Accili D, Cama A, McKeon C. Mutations in insulin-receptor gene in insulinresistant patients. Diabetes Care 1990;13(3):257-279.

8. Rojek A, Niedziela M. Insulin receptor and its relationship with different forms of insulin resistance. Postepy Biol Kom (Adv Cell Biol) 2009;36(4): 617-648.

9. Rojek A, Niedziela M. Podloze molekularne zespolu Rabsona-Mendenhalla (Molecular background of RabsonMendenhall syndrome). Endokrynol Pediatr (Pediatr Endocrinol) 2009;8(2)27:67-78.

10. Leprechaunism no. 246200: defect in insulin receptor, with Donohue syndrome. Online Mendelian Inheritance in Man (OMIM). Johns Hopkins University. Creation date - Victor A.McKusick: 6/3/1986.

http://www.ncbi.nlm.nih.gov/entrez/dispomim.cgi?id=246200 (2010-10-03).

11. Rabson-Mendenhall syndrome. 262190: Pineal hyperplasia, insulin-resistant diabetes mellitus, and somatic abnormalities. Online Mendelian Inheritance in Man (OMIM). Johns Hopkins University. Creation date - Victor A. McKusick: 6/4/1986. http://www.ncbi.nlm.nih.gov/entrez/dispomim.cgi?id=262190 (2010-10-03).

12. Al-Gazali LI, Khalil M, Devadas KA. A syndrome of insulin resistance resembling leprechaunism in five sibs of consanguineous parents. J Med Genet 1993;30:470-475.

13. Backeljauw PF, Alves C, Eidson M, Cleveland W, Underwood LE, Davenport ML. Effect of intravenous insulinlike growth factor I in two patients with leprechaunism. Pediatr Res 1994;36:749-754. 
14. Donohue WL, Uchida I. Leprechaunism: an euphemism for a rare familial disorder. J Pediatr 1954;45:505-519.

15. Jospe N, Zhu J, Liu R, Livingston JN, Furlanetto RW. Deletion of 3 basepairs resulting in the loss of lysine-121 in the insulin receptor alpha-subunit in a patient with leprechaunism: binding, phosphorylation, and biological activity. J Clin Endocrinol Metab 1994;79:1294-1302.

16. Cochran E, Young JR, Sebring N, De Paolli A. Efficacy of recombinant methionyl human leptin therapy for the extreme insulin resistance of the Rabson-Mendenhall Syndrome. J Clin Endocrinol Metab 2004;89(4):1548-1554.

17. Hardaway CA, Gibbs NF. What Syndrome Is This? Pediatr Dermatol 2002;19(3): 267-270.

18. Harris AM, Hall B, Kriss VM, Fowlkes JL, Kiessling SG. Rabson-Mendenhall syndrome: medullary sponge kidney, a new component. Pediatr Nephrol 2007;22:2141-2144.

19. Kirby E, Beals D. Fibroepithelial papillomatosis ("skin tags") in Rabson-Mendenhall syndrome. J Pediatr Surg 2008;43:E21-E26.

20. Tuthill A, Semple RK, Day R et al. Functional characterization of a novel insulin receptor mutation contributing to Rabson-Mendenhall syndrome. Clin Endocrinol 2007;66:21-26.

21. Rabson SM, Mendenhall EN. Familial hypertrophy of pineal body, hyperplasia of adrenal cortex and diabetes mellitus; report of 3 cases. Am J Clin Pathol 1956;26:283-290.

22. Donohue WL. Dysendocrinism. J Pediatr 1948;32:739-748.

23. Longo N, Wang Y, Smith SA, Langley SD, Dimeglio LA, Gianella-Neto D. Genotype-phenotype correlation in inherited severe insulin resistance. Hum Mol Genet 2002;11(12):1465-1475.

24. Garret TP, McKern NM, Lou M, Frenkel MJ, Bentley JD, Lovrecz GO, Elleman TC, Cosgrove LJ, Ward CW. Crystal structure of the first three domains of the type-1 insulin-like growth factor receptor. Nature 1998;394:395-399.

25. Elsas LJ, Endo F,Strumlauf E, Elders J, Priest JH. Leprechaunism: an inherited defect in a high-affinity insulin receptor. Am J Hum Genet 1985;37:73-88.

26. Elders MJ, Schedewie HK, Olefsky J, B.Givens, F Char, DM Bier, D Baldwin, RA Fiser, S Seyedabadi, A

Rubenstein. Endocrine-metabolic relationship in patients with Leprechaunism. J Natl Med Assoc 1982;74(12):1195-1210.

27. Semple RK, Sleigh A, Murgatroyd PR et al. Postreceptor insulin resistance contributes to human

dyslipidemia and hepatic steatosis. J Clin Invest 2009;119(2):315-22.

28. Semple RK. EJE PRIZE 2015: How does insulin resistance arise, and how does it cause disease? Human genetic lessons. Eur J Endocrinol 2016;174(5):R209-23.

29. Psiachou H, Mitton S, Alaghband-Zadeh J, Hone J, Taylor SI, Sinclair L. Leprechaunism and homozygous nonsense mutation in the insulin receptor gene (Letter). Lancet1993;342:924.

30. Kadowaki T, Kadowaki H, Rechler M. Five mutant alleles of the insulin receptor gene in patients with genetic forms of insulin resistance. J Clin Invest 1990;86:254-264.

31. Nakae J, Kato M, Murashita M, Shinohara N, Tajima T, Fujieda K. Long-term effect of recombinant human insulin-like growth factor I on metabolic and growth control in a patient with leprechaunism. J Clin Endocrinol Metab 1998;83:542-549.

32. Longo N, Singh R, Griffin LD, Langley SD, Parks JS, Elsas LJ. Impaired growth in Rabson-Mendenhall syndrome: Lack of effect of growth hormone and insulin-like growth factor I. J Clin Endocrinol Metab 1994;79:799-805.

33. De la Fuente MC, Castellanos RB, Blanco MA. Long survival in Rabson-Mendenhall syndrome. Diabetes Res Clin Pract 2010;89:e17-e18.

Table 1. The glucose and insulin values for the patient serum

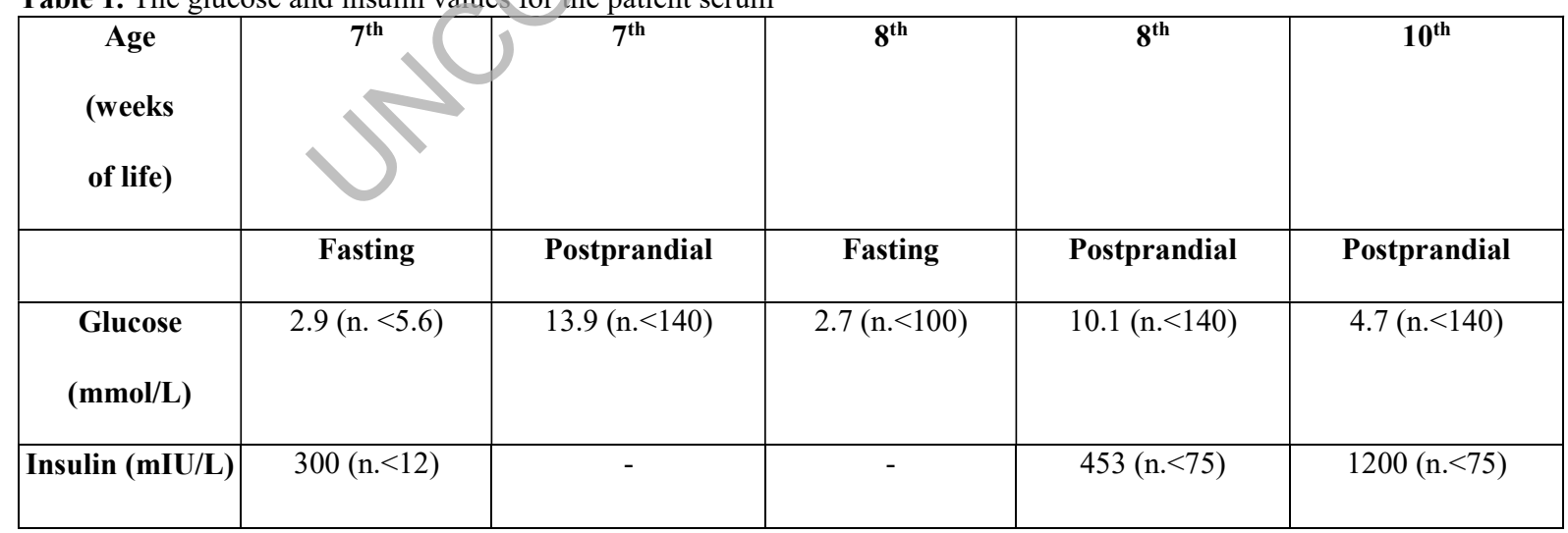

Figure 1. The sequence analysis of the INSR gene 


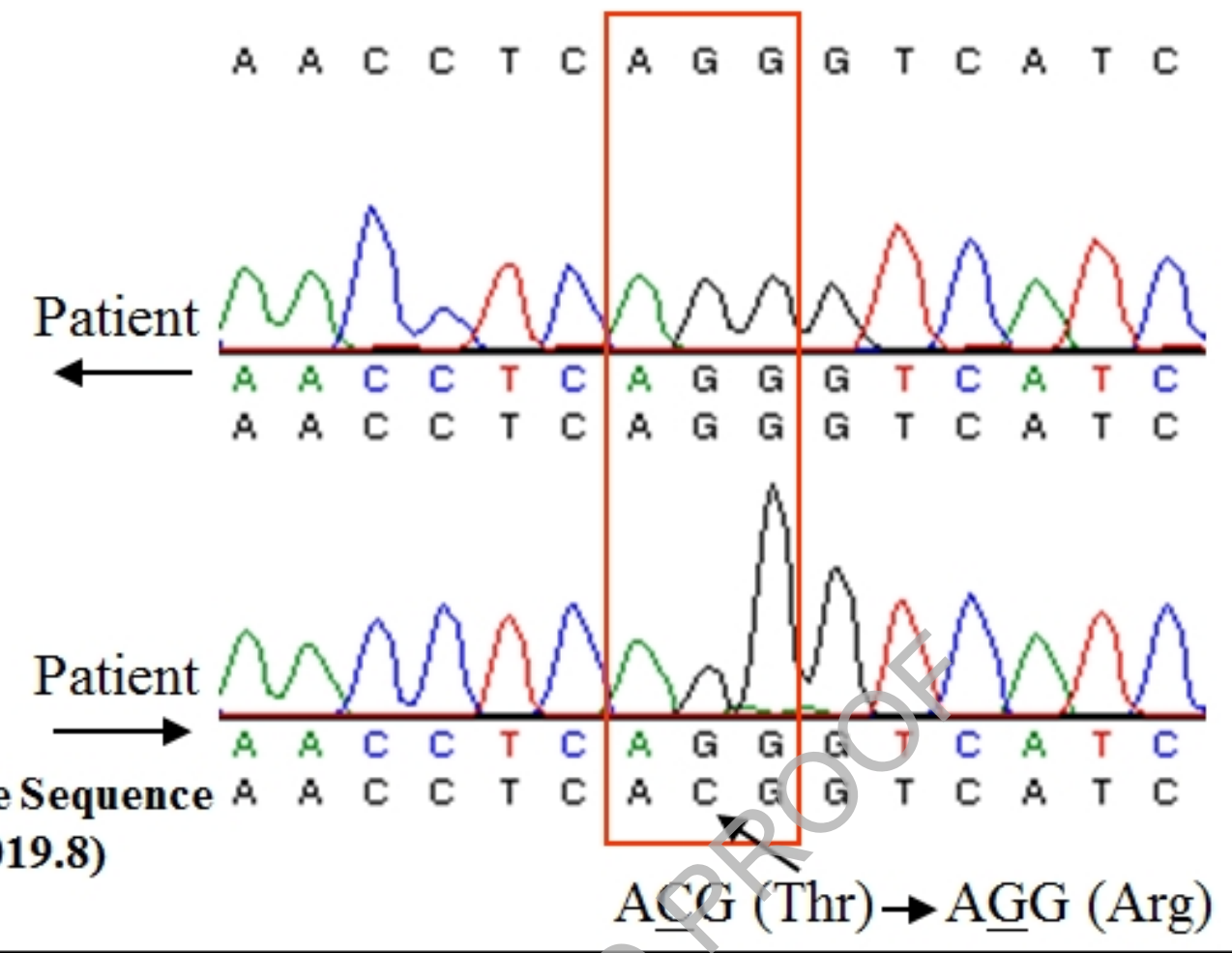

